\title{
Anatomic repair of Ebstein's anomaly with isolated anterior leaflet downward displacement
}

\author{
Qingyu Wu, MD, Guangyu Pan, MD, Hongyin Li, MD, and Xiangchen Kong, MD Candidate
}

Objective: Ebstein's anomaly with isolated anterior leaflet downward displacement is rare and has not been reported in the literature to our knowledge. In this article, our experience of the surgical treatment in 6 cases with this anomaly is reported.

\begin{abstract}
Methods: From November 2005 to November 2013, 6 patients (3 male, 3 female, aged 2-39 years) with Ebstein's anomaly and isolated anterior leaflet downward displacement received anatomic repair at the First Hospital of Tsinghua University. The diagnosis was made by echocardiography and confirmed at operation. Surgery was performed under hypothermic cardiopulmonary bypass. Surgical technique included excision of a huge atrialized portion of the right ventricle located in the anterior wall of the heart; reconstruction of the right ventricle by repairing the "V"-shaped defect left by the excision procedure; detachment, repair, and reimplantation of the anterior leaflet; and reconstitution of the right atrioventricular connection. Intraoperative transesophageal echocardiography was used to evaluate the position, morphology, structure, and function of the tricuspid valve, as well as right ventricular function.
\end{abstract}

Results: Five patients were discharged uneventfully, and 1 patient died of postoperative pneumonia. At follow-up from 2 months to 7 years, no notable tricuspid valve regurgitation or stenosis was found and all patients were maintaining a normal lifestyle. The 27 -year-old female patient gave birth to a normal infant uneventfully 3 years after surgery.

Conclusions: Ebstein's anomaly with isolated anterior leaflet downward displacement is a complex and severe abnormality, and has several unique anatomic and clinical features and specific surgical requirements. Preoperative diagnosis can be made by clinical investigation and echocardiography. Excellent results can be achieved by anatomic correction. (J Thorac Cardiovasc Surg 2014;148:1454-8)

Supplemental material is available online.

The most common morphologic change in Ebstein's anomaly (EA) is that the septal and posterior leaflets displace downward, with the anterior leaflet remaining in the normal position. ${ }^{1,2}$

It is rare for the anterior leaflet to displace downward in isolation with the septal and posterior leaflets remaining in the normal position, although both leaflets may be hypoplastic. There are no reports of cases with this kind of abnormality in the English or Chinese literature. The surgical techniques described for the more standard EA have not yet identified the morphologic abnormality found in this malformation. Six patients with this abnormality

\footnotetext{
From the Heart Center, First Hospital of Tsinghua University, Beijing, China. Disclosures: Authors have nothing to disclose with regard to commercial support.

Received for publication Nov 21, 2013; revisions received Feb 21, 2014; accepted for publication Feb 26, 2014; available ahead of print March 31, 2014.

Address for reprints: Qingyu Wu, MD, No. 6 Jiuxianqiao 1st Rd, Beijing,

China 100016 (E-mail: wuqingyu@mail.tsinghua.edu.cn).

0022-5223/\$36.00

Copyright (c) 2014 by The American Association for Thoracic Surgery

http://dx.doi.org/10.1016/j.jtcvs.2014.02.075
}

underwent anatomic repair at the First Hospital of Tsinghua University. Excellent results were achieved in 5 patients. Our experience with a novel surgical technique is reported.

\section{CLINICAL DATA}

From November 2005 to November 2013, 6 patients with EA and isolated anterior leaflet downward displacement (3 male, 3 female, age 2-39 years, weight 10-61 kg) received surgical treatment in the First Hospital of Tsinghua University. Among them, a 2-year-old boy was diagnosed by fetal echocardiography in the 38th week of pregnancy and then had poor development and low activity tolerance after birth. The other 5 patients presented with weakness, palpitations after activity, chest tightness, and frequent respiratory tract infections.

All patients were diagnosed through preoperative physical examination, electrocardiogram, chest $\mathrm{x}$-ray, and ultrasonic echocardiogram (UCG). The electrocardiogram showed complete right bundle branch block in 3 patients, incomplete right bundle branch block in 2 patients, atrial fibrillation in 1 patient, and ventricular premature beat in 1 patient. Chest x-ray showed decreased pulmonary blood flow, right atrial enlargement, and cardiothoracic ratio of 0.58 to 0.90 (Figure 1, A). UCG was used to evaluate the morphology, position, structure, and regurgitation degree 

Abbreviations and Acronyms
ASD $=$ atrial septal defect
$\mathrm{CT}=$ computed tomography
EA = Ebstein's anomaly
$\mathrm{PFO}=$ patent foramen ovale
$\mathrm{RCA}=$ right coronary artery
$\mathrm{TV}=$ tricuspid valve
$\mathrm{UCG}=$ ultrasonic echocardiogram

of the tricuspid valve (TV) (Figure 1, $B$ and $C$ ), in addition to atrialized ventricle size, mitral valve function, and both right and left ventricular function. Three patients underwent computed tomography (CT) scan, which showed right ventricular enlargement, a giant atrialized right ventricle located in the anterior wall of the functional right ventricle, anterior leaflet downward displacement, and annulus enlargement. One patient underwent cardiac magnetic resonance imaging. The 29 -year-old female patient was misdiagnosed with idiopathic right atrial dilatation at another institution by UCG and cardiac CT. One patient with this condition had an associated atrial septal defect (ASD), and 5 patients had a patent foramen ovale (PFO). Cardiac function of the 6 patients was New York Heart Association grade II to III. TV regurgitation was moderate in 2 patients and severe in 4 patients (Table 1).

\section{METHODS}

Anatomic surgical repair was performed in all patients. After sternotomy, the pericardium was opened, cardiopulmonary bypass was established routinely, and hypothermia was commenced. When the patient's core temperature reached $30^{\circ} \mathrm{C}$, the aorta was clamped. Cold crystalloid cardioplegia solution was perfused via the aortic root for cardiac protection.

Intraoperative exploration confirmed that all patients had a huge atrialized ventricle located in the anterior of the heart with a thin wall forming a large cystic space (Figure 2). The inferior margin of the cyst abutted the anterior wall of the functional right ventricle at least $2 \mathrm{~cm}$ below the "V"-shaped defect. The anterior leaflet attached along the edge of the "V"-shaped defect was narrow, poorly developed, and significantly displaced downward. The posterior and septal leaflets were in a normal position in all patients. The TV annulus was enlarged and did not form a complete ring. It appeared that after repair, the papillary muscle positions and the size of the right ventricle would be almost normal.

After excision of the atrialized right ventricle, there was now an obvious "V"-shaped defect in the anterior wall of the right ventricle. The right coronary artery (RCA) ran along the inferior margin of the atrialized right ventricle in 5 patients and across the roof of the atrialized right ventricle in 1 patient. ASD was confirmed in 1 patient, and PFO was confirmed in 5 patients.

Excision of the redundant atrialized right ventricle wall, paying close attention to protection of the RCA and retention of part of the atrialized ventricular wall to establish a right atrioventricular connection was completed. As a result of excision of the giant atrialized right ventricle, the loss of integrity of the atrioventricular annulus and right ventricle caused by the huge "V"-shaped defect was revealed (Figure 3, Al and $A 2)$. It was necessary to suture the edge of the defect directly side-toside to repair the right ventricular anterior wall and to construct a TV annulus of normal size to achieve normal geometry of the right ventricle The anterior leaflet was detached from its base close to the defective edge of the anterior wall of the right ventricle. If the chordae tendineae were short and restricting the motion of leaflets, they were transected (Figure 3, A1 and A2). To reconstruct the detached anterior leaflet, the detached base of the leaflet was enfolded by sutures to narrow this edge but lengthen the leaflet in its proximal-distal dimension. This resulted in an increase in the effective area of the leaflet when reattached in the normal annular position (Figure 3, $B$ and $D$ ). A piece of fresh autologous pericardium was used to enlarge the poorly mobile septal leaflet in 5 patients (Figure 3, Cl and $C 2$ ). Care was taken to obtain proper coaptation of the 3 leaflets so that the TV exhibited no stenosis or insufficiency (Figure 3,D). Subsequently, the ASD or PFO was closed, suturing the remaining partially atrialized ventricle wall and right atrium wall to reestablish a stable right atrioventricular connection and achieve atrial closure to nearly normal size (Figure E1). The extended RCA was fixed to avoid kinking (Figure E2).

After evacuation of air from all chambers, the aortic clamp was released and the heart was restarted. There were no complications in weaning from cardiopulmonary bypass in any patient. The chest was closed, and surgery was completed (Table 2). The hemodynamic status of all patients remained stable in our group in the postoperative period with only a restricted use of dopamine and nitroglycerin. Central venous pressure was maintained at 6 to $8 \mathrm{~mm} \mathrm{Hg}$ to minimize right ventricular preload.

\section{RESULTS}

Five patients recovered fully and were discharged uneventfully. One patient died of severe sepsis due to pneumonia 4 weeks after surgery.

\section{Follow-up}

The follow-up period was from 2 months to 7 years in 5 patients. UCG showed tricuspid leaflets in the normal position and functioning well with no stenosis in all patients, no regurgitation in 3 patients, and mild regurgitation in 2 patients (Figure $1, D-F$ ). All patients were maintaining a normal lifestyle, and their cardiac function improved to New York Heart Association grade I. One patient gave birth uneventfully 3 years after surgery.

\section{DISCUSSION}

EA exhibits varied morphologic changes, which usually include atrialized right ventricle formation and tricuspid annulus enlargement. The leaflets may be hypoplastic and may have limited movement to different degrees in individual leaflets. It is most common that the septal and posterior leaflets are displaced downward, hypoplastic, or even absent, whereas the anterior leaflet is in a normal position. It is rare to find only the anterior leaflet abnormal and displaced downward while the septal and posterior leaflets remain in a normal position. To our knowledge, there is no report of this kind in the literature. In this group, there was a huge atrialized right ventricle to the anterior of the heart associated with several other unique pathologic features. Consequently, the surgical treatment must be different, even though the clinical symptoms may be almost the same as in most patients with EA. 

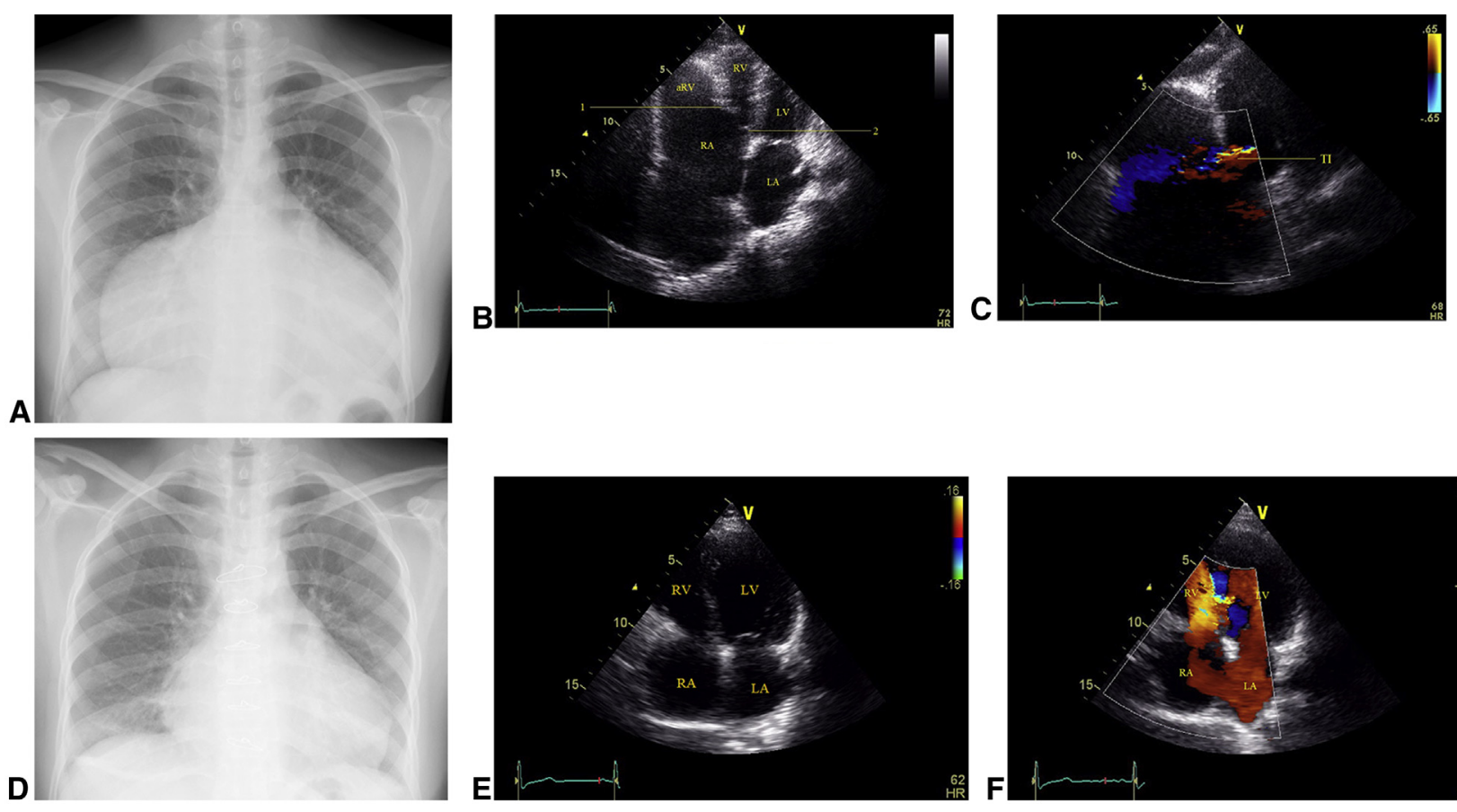

FIGURE 1. Imaging examination. A, Preoperative chest $x$-ray shows a significantly enlarged right heart. B and C, Preoperative UCG. 1. Anterior tricuspid leaflet. 2. Septal tricuspid leaflet. D, Postoperative chest x-ray shows significantly reduced heart size. E and F, Postoperative UCG shows normal-sized right atrium and right ventricle with no notable tricuspid insufficiency. $a R V$, Atrialized right ventricle; $L A$, left atrium; $L V$, left ventricle; $R A$, right atrium; $R V$, right ventricle; $T I$, tricuspid insufficiency.

\section{Diagnosis}

Because this variant is uncommon, it is easily misdiagnosed before surgery. Compared with the general group of patients with EA, this cohort has similar symptoms, such as palpitations, shortness of breath, limitation of activity, and restricted development. However, the data from chest x-ray, CT scan, magnetic resonance imaging, and UCG are characteristic, for example, chest $\mathrm{x}$-ray shows significant right heart enlargement, and UCG in particular assists in making the correct diagnosis by identification of a huge right atrium lying anteriorly and an atrialized right ventricle, a downward displaced anterior leaflet, normally positioned posterior and septal leaflets, and severe tricuspid incompetence.

\section{Pathologic Structure}

First, in the general group of patients with EA, the atrialized ventricle usually lies above the downward

TABLE 1. Patients' data

\begin{tabular}{lccccccc}
\hline $\begin{array}{c}\text { Patient } \\
\text { no. }\end{array}$ & Gender & $\begin{array}{c}\text { Age } \\
(\mathbf{y})\end{array}$ & $\begin{array}{c}\text { RA } \\
(\mathbf{c m})\end{array}$ & $\begin{array}{c}\text { aRV } \\
(\mathbf{c m})\end{array}$ & $\begin{array}{c}\text { AL dd } \\
(\mathbf{c m})\end{array}$ & $\begin{array}{c}\text { SL } \\
\text { hyperplasia }\end{array}$ & $\begin{array}{c}\text { PL } \\
\text { normal }\end{array}$ \\
\hline 1 & $\mathrm{M}$ & 2 & 5.8 & $6 * 8$ & 5 & $\mathrm{Y}$ & $\mathrm{Y}$ \\
2 & $\mathrm{~F}$ & 6 & 7.8 & $12 * 15$ & Severe & $\mathrm{Y}$ & $\mathrm{Y}$ \\
3 & $\mathrm{~F}$ & 27 & 9.1 & $6 * 5$ & 7 & $\mathrm{~N}$ & $\mathrm{Y}$ \\
4 & $\mathrm{~F}$ & 29 & 5.5 & $10 * 8$ & 5 & $\mathrm{Y}$ & $\mathrm{Y}$ \\
5 & $\mathrm{M}$ & 39 & 10 & $12 * 10$ & 4 & $\mathrm{Y}$ & $\mathrm{Y}$ \\
6 & $\mathrm{M}$ & 5 & 5.9 & $10 * 8$ & 3.5 & $\mathrm{Y}$ & $\mathrm{Y}$ \\
\hline
\end{tabular}

$A L$, Anterior leaflet; $a R V$, atrialized right ventricle; $d d$, downward displacement; $P L$, posterior leaflet; $R A$, right atrium; $S L$, septal leaflet. displaced leaflets located on the right posterior aspect of the right ventricle. However, in our cohort the atrialized ventricle (which is huge, cystic, and thin walled) is at the front of the heart because of the anterior leaflet's downward displacement. The inferior margin of the atrialized ventricle abuts the anterior wall of the functional right ventricle at least $2 \mathrm{~cm}$ below the huge "V"-shaped defect. Along the edge of this defect where the anterior leaflet is attached, the leaflet is abnormal, the base of the leaflet is longer, and the distance from base to free edge is shorter. The main chordae and papillary muscles are in a normal position; some short chordae may be correspondingly abnormal. Second, the septal leaflet (often dysplastic) and posterior leaflet are in a normal position; the septal leaflet is underdeveloped with limited movement. Third, the RCA is longer and may run along the atrialized ventricular surface or more commonly along the inferior margin of the atrialized right ventricle.

\section{Operative Indications}

The patient has clinical symptoms of moderate to severe TV insufficiency, significant cardiac enlargement, and cardiac dysfunction. Surgery should be considered when the preoperative diagnosis is clearly established.

\section{Surgical Technique}

Previous techniques ${ }^{3-7}$ to correct Ebstein's deformity (including TV replacement) are insufficient to reconstruct 


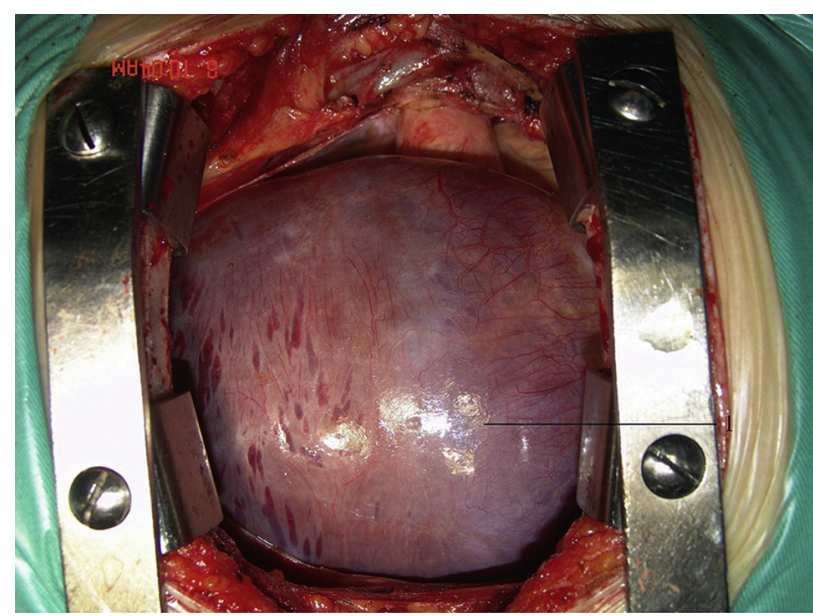

FIGURE 2. Huge, thin-walled atrialized right ventricle.

this variant. However, the basic method and principle of this technique remain anatomic correction, ${ }^{8-10}$ which includes the following: (1) We excise the atrialized ventricle and valve ring enfoldment, and (2) detach the downward displaced leaflet, repair, reimplantation, and transection of those chordae tendineae and papillary muscle that restrict leaflet motion. In our new technique, the purpose of leaflet repair, as described in the "Methods" section, is to increase the anterior leaflet area by enfolding its longer base to increase the leaflet's length from base to free edge and to mobilize tethering. A piece of autologous pericardium can be used to enlarge the area of the septal leaflet if required. Because the septal and posterior leaflets are in a normal position, they need no detachment or reimplantation; thus, the risk of atrioventricular block is avoided. (3) We repair the "V"-shaped defect that remains after excision of the atrialized ventricle, reconstruct the right ventricle and TV annulus to normal size, create complete 3-leaflet coaptation, and avoid stenosis. (4) We establish a new connection between the right atrium and ventricle by repairing the walls of the partially atrialized ventricle and right atrium. (5) We fix the RCA to the surface of the heart (in cases of significant RCA lengthening) to prevent kinking (Figure E2). (6) We use transesophageal ultrasound to confirm adequate TV and right ventricular function.

\section{CONCLUSIONS}

EA with isolated anterior leaflet downward displacement is a rare and complex condition. Preoperative diagnosis is
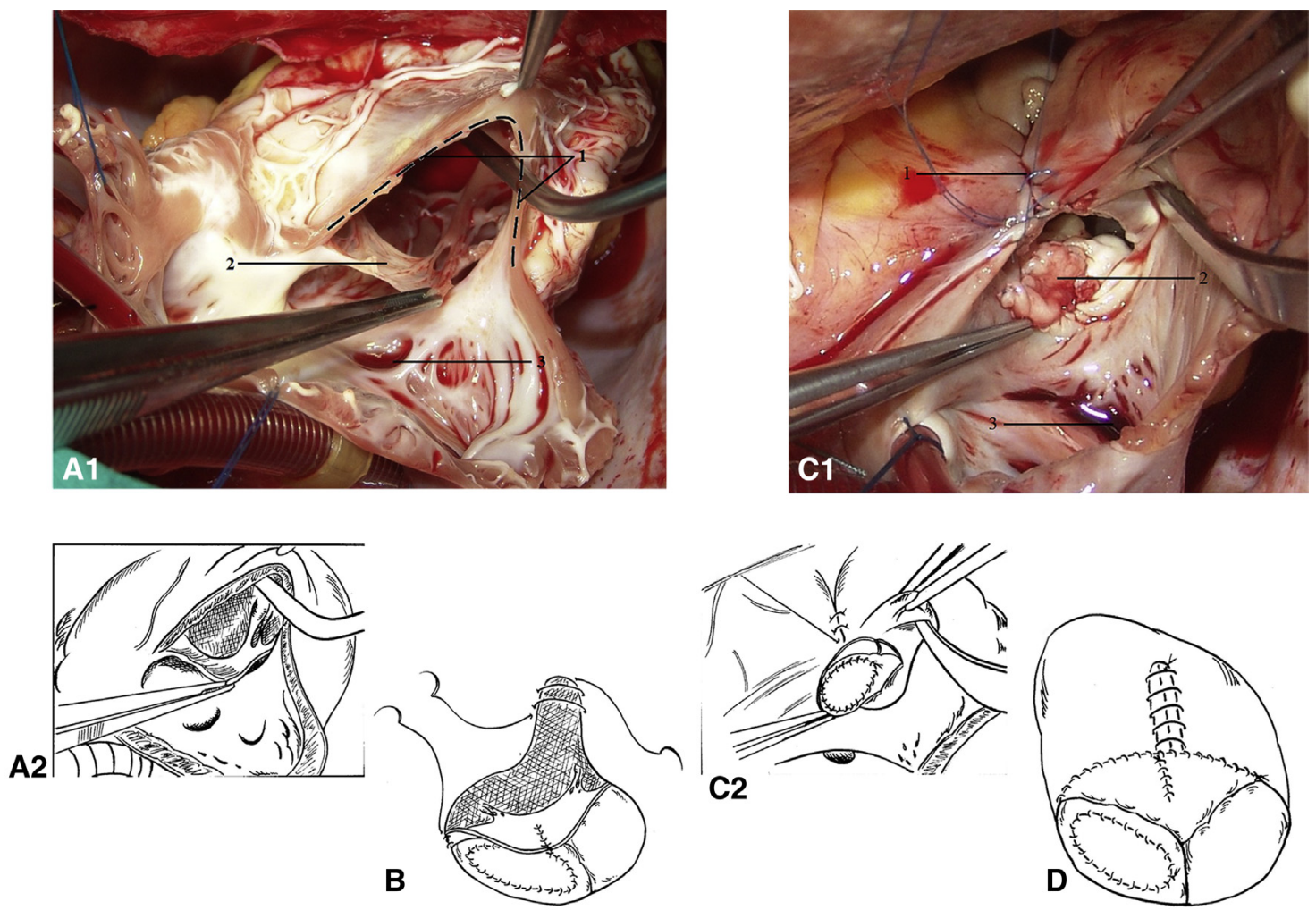

FIGURE 3. Procedure: A1 and A2, After atrialized right ventricle excision. A1, 1 , Huge "V"-shaped defect left by atrialized right ventricle excision; 2, anterior tricuspid leaflet (mostly detached); 3, coronary sinus. B, "V" defect and anterior leaflet repair. C1 and C2, Increased septal leaflet area. $\mathrm{C} 1,1$, Suture of the "V"-shaped defect to reconstruct the right ventricular anterior wall and TV annulus; 2, enlarged septal leaflet with autologous pericardium; 3, coronary sinus. D, Completed procedure. 
TABLE 2. Surgical technique

\begin{tabular}{lccccc}
\hline & $\begin{array}{c}\text { ARV } \\
\text { Patient } \\
\text { excision }\end{array}$ & $\begin{array}{c}\text { repair, and } \\
\text { reimplant }\end{array}$ & $\begin{array}{c}\text { SL } \\
\text { patched }\end{array}$ & $\begin{array}{c}\text { Reconstruction } \\
\text { of RV and TA }\end{array}$ & $\begin{array}{c}\text { Reestablish } \\
\text { RA-RV } \\
\text { connection }\end{array}$ \\
\hline 1 & $\mathrm{Y}$ & $\mathrm{Y}$ & $\mathrm{Y}$ & $\mathrm{Y}$ & $\mathrm{Y}$ \\
2 & $\mathrm{Y}$ & $\mathrm{Y}$ & $\mathrm{Y}$ & $\mathrm{Y}$ & $\mathrm{Y}$ \\
3 & $\mathrm{Y}$ & $\mathrm{Y}$ & $\mathrm{N}$ & $\mathrm{Y}$ & $\mathrm{Y}$ \\
4 & $\mathrm{Y}$ & $\mathrm{Y}$ & $\mathrm{Y}$ & $\mathrm{Y}$ & $\mathrm{Y}$ \\
5 & $\mathrm{Y}$ & $\mathrm{Y}$ & $\mathrm{Y}$ & $\mathrm{Y}$ & $\mathrm{Y}$ \\
6 & $\mathrm{Y}$ & $\mathrm{Y}$ & $\mathrm{Y}$ & $\mathrm{Y}$ & $\mathrm{Y}$ \\
\hline
\end{tabular}

$A L$, Anterior leaflet; $a R V$, atrialized right ventricle; $R A$, right atrium; $R V$, right ventricle; $S L$, septal leaflet; $T A$, tricuspid annulus.

possible. Anatomic correction using a novel and versatile technique based on sound surgical principles allows reconstruction of the functional TV and restoration of the geometry and function of the right ventricle and mainteneance of coronary artery integrity. This affords the majority of patients the opportunity to attain a normal lifestyle.

The authors thank Drs Daniel Edward Porter and Yuanxin Nie, who helped with the English language modification.

\section{References}

1. Radford DJ, Graff RF, Neilson GH. Diagnosis and natural history of Ebstein's anomaly. Br Heart J. 1985;54:517-22.

2. Kouchoukos NT, Blackstone EH, Doty DB, Hanley FL, Karb RB. Issue 28. In: Kirklin/Barratt-Boyes Cardiac Surgery. 3rd ed. Volume 2, 3rd ed. London: Churchill Livingstone; 2003:1178.

3. Attenhofer Jost CH, Connolly HM, Dearani JA, Edwards WD, Danielson GK. Ebstein's anomaly. Circulation. 2007;115:277-85.

4. Carpentier A, Chauvaud S, Macé L, Relland J, Mihaileanu S, Marino JP, et al A new reconstructive operation for Ebstein's anomaly of the tricuspid valve J Thorac Cardiovasc Surg. 1988;96:92-101.

5. Chauvaud S. Ebstein's malformation. Surgical treatment and results. J Thorac Cardiovasc Surg. 2000;48:220-3.

6. Chauvaud S, Berrebi A, d'Attellis N, Mousseaux E, Hernigou A, Carpentier A. Ebstein's anomaly: repair based on functional analysis. Eur J Cardiothorac Surg. 2003;23:525-31.

7. da Silva JP, Baumgratz JF, da Fonseca L, Franchi SM, Lopes LM, Tavares GM, et al. The cone reconstruction of the tricuspid valve in Ebstein's anomaly. The operation: early and midterm results. J Thorac Cardiovasc Surg. 2007; 133:215-23.

8. Wu Q, Huang Z, Pan G, Wang L, Li L, Xue H. Early and midterm results in anatomic repair of Ebstein anomaly. J Thorac Cardiovasc Surg. 2007;134: 1438-40.

9. Wu Q, Huang Z. A new procedure for Ebstein's anomaly. Ann Thorac Surg. 2004; 77:470-6.

10. Wu Q, Huang Z. Anatomic correction of Ebstein anomaly. J Thorac Cardiovasc Surg. 2001;122:1237-8. 


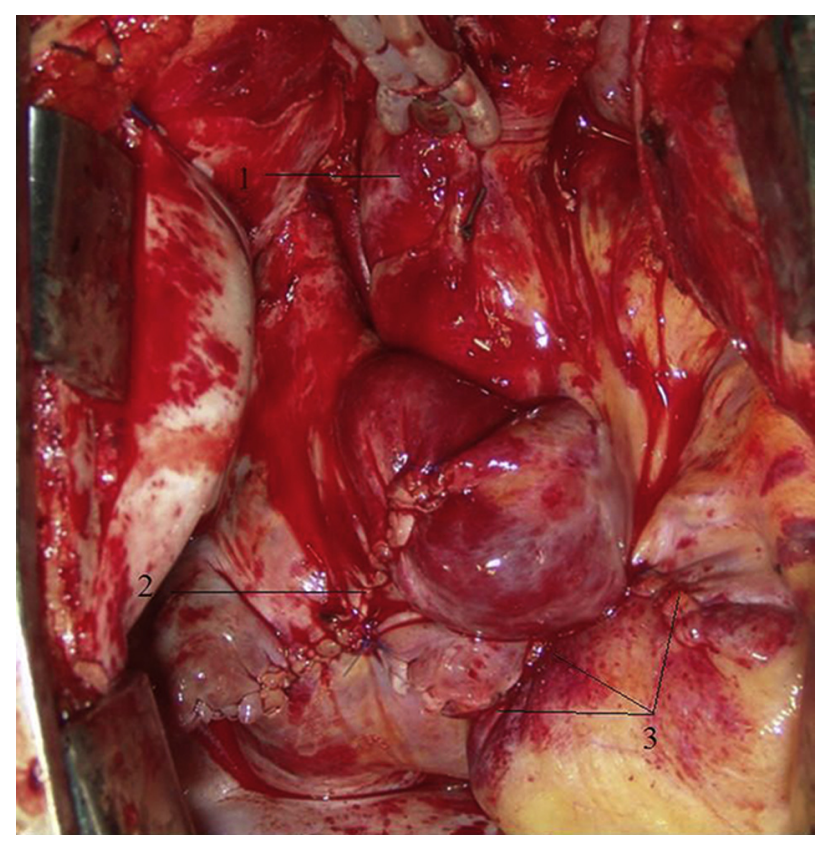

FIGURE E1. Reestablished right atrioventricular connection. 1, Ascending aorta. 2, Right atrial incision (closed). 3, Reestablished right atrioventricular connection.

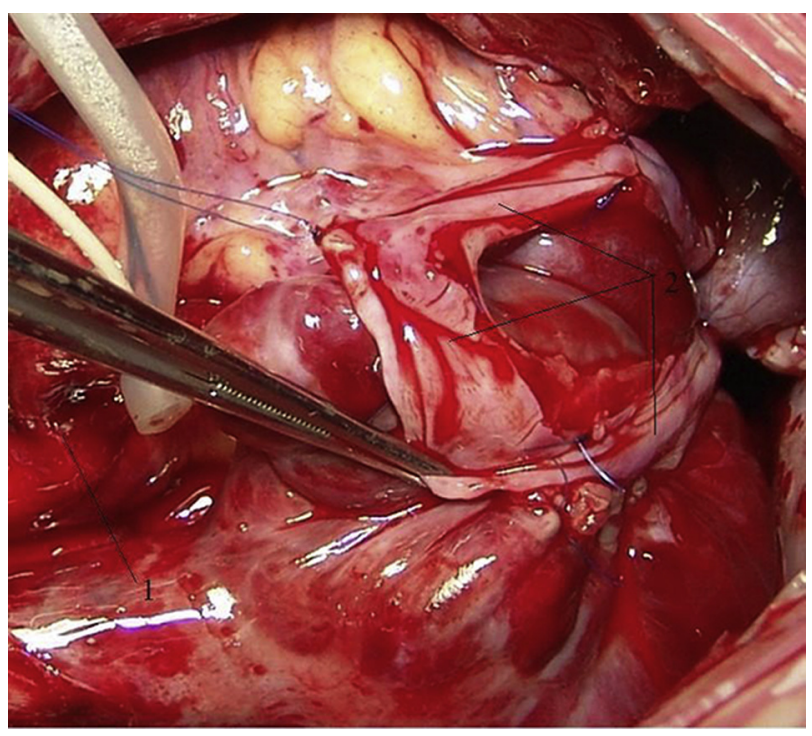

FIGURE E2. Protecting the extended RCA. 1, Ascending aorta. 2, Fix the extended RCA. 